\title{
Changing labour market conditions during the 'great recession' and mental health in Scotland 2007-2011: an example using the Scottish Longitudinal Study and data for local areas in Scotland
}

\author{
Sarah Curtis ${ }^{\mathrm{a}, \mathrm{b}, *}$, Jamie Pearce ${ }^{\mathrm{b}, \mathrm{c}}$, Mark Cherrie ${ }^{\mathrm{b}}$, Christopher Dibben ${ }^{\mathrm{b}, \mathrm{c}}$, Niall Cunningham ${ }^{\mathrm{a}}$, \\ Clare Bambra ${ }^{\mathrm{d}}$ \\ ${ }^{a}$ Department of Geography, Durham University, UK \\ ${ }^{\mathrm{b}}$ Centre for Research on Environment, Society and Health, School of GeoSciences, University of Edinburgh, UK \\ ${ }^{\mathrm{c}}$ ESRC Administrative Data Research Centre, University of Edinburgh, UK \\ ${ }^{\mathrm{d}}$ Medical School, Newcastle University, UK
}

\section{A R T I C L E I N F O}

\section{Keywords:}

Mental health

Economic recession

Scotland

Health geography

\begin{abstract}
A B S T R A C T
This paper reports research exploring how trends in local labour market conditions during the period 2007-2011 (early stages of the 'great recession') relate to reported mental illness for individuals. It contributes to research on spatio-temporal variation in the wider determinants of health, exploring how the lifecourse of places relates to socio-geographical inequalities in health outcomes for individuals. This study also contributes to the renewed research focus on the links between labour market trends and population health, prompted by the recent global economic recession. We report research using the Scottish Longitudinal Study (SLS), a 5.3\% representative sample of the Scottish population, derived from census data (https://sls.lscs.ac.uk/). In Scotland, (2011) census data include self-reported mental health. SLS data were combined with non-disclosive information from other sources, including spatio-temporal trends in labour market conditions (calculated using trajectory modelling) in the 32 local authority areas in Scotland. We show that, for groups of local authorities in Scotland over the period 2007-2011, trends in employment varied. These geographically variable trends in employment rates were associated with inequalities in self-reported mental health across the country, after controlling for a number of other individual and neighbourhood risk factors. For residents of regions that had experienced relatively high and stable levels of employment the odds ratio for reporting a mental illness was significantly lower than for the 'reference group', living in areas with persistently low employment rates. In areas where employment declined markedly from higher levels, the odds ratio was similar to the reference group. The findings emphasise how changes in local economic conditions may influence people's health and wellbeing independently of their own employment status. We conclude that, during the recent recession, the economic life course of places across Scotland has been associated with individual mental health outcomes.
\end{abstract}

\section{Main text}

This paper reports on research exploring how changing local labour market conditions during the recent 'great recession' (the major global economic downturn beginning 2007/2008) relate to reported mental illness in Scotland. This research contributes to a growing body of international literature (reviewed below) suggesting that the public health impacts of the 'great recession' have been significant and widespread, associated with various health outcomes including for mental health. However, the pathways connecting economic shocks and mental health over time remain poorly understood, and it is less clear whether some communities and regions within countries are particularly vulnerable to these economic circumstances. In addressing these questions, the paper also contributes to research examining how spatiotemporal variation of environmental risk factors developing over the lifecourse of places may relate to inequalities in health outcomes for individuals (Matthews, 2017; Murray et al., 2013; Lekkas et al., 2017; Pearce, 2018). Recent work on the lifecourse of place has shown that there can be critical periods during life when places can influence subsequent health outcomes, often much later in life (Pearce et al., 2018). Work in this area is also showing that the influence of place can be accumulative, with place-based characteristics at different points in

\footnotetext{
* Corresponding author. Durham University, Geography Dept, South Rd, Durham, DH1 3LE, UK.

E-mail address: s.e.curtis@durham.ac.uk (S. Curtis).
} 
life combining synergistically to shape individual health trajectories (Kwan, 2004; Gatrell, 2011; Norman and Boyle, 2014; Cherrie et al., 2018). This is an agenda which presents challenges for quantitative research, as discussed below. The research presented here also contributes to the debate regarding the complex relationship between individual and contextual risks for health (Macintyre et al., 2002; Smith and Easterlow, 2005; Cummins, et al., 2007; Bambra, 2016), since we illustrate here (both with reference to other research and from our own findings) how living in areas that are impacted by economic recession may have significance for health and wellbeing of local people, even if they do not themselves become unemployed.

\section{Background to the research - a review of existing evidence}

It is widely recognized that health inequality is importantly affected by the 'wider' (social) determinants of individual health (WHO, 2008), which operate across local communities, at the 'collective' (or 'contextual') as well as the individual level, and that these processes are complex, operating differently over time for different socio-demographic groups and in different settings (Diez-Roux and Mair, 2010; Bailey, 2009; Curtis and Riva, 2010; Pearce, 2018). Rigorous research on determinants of population health is increasingly being used to inform action on 'place shaping for health' in sectors outside the medical services, as well as in the fields of public and community health services (Learmonth and Curtis, 2013; NHS Scotland, 2018). Evidence from research can help us understand the potential health impacts of changing socio-economic conditions at the local scale, within countries, and also internationally. In this respect, research which examines these wider determinants of health from a temporal as well as a spatial perspective is especially relevant.

Employment conditions are known to be important as 'wider determinants' of health (Bartley et al., 2006; Paul and Moser, 2009; Bambra, 2011; Riva et al., 2011; Popham et al., 2012; Columbo et al., 2018; Van der Wel et al., 2018) but the nature, scale and significance of relationships between health and labour market effects over time are not fully understood. This argument is emphasised in a number of commentaries and reviews conducted from an international perspective (Faculty of Public Health (undated); Ferrarini et al., 2014; Glonti et al., 2015; Laaksonen et al., 2009; Meltzer et al., 2010; NHS Health Scotland, 2015; Reeves et al., 2015; ScotPHO, 2012; Tefft, 2011; Toffolutti and Suhrcke, 2014; Uutela, 2010). Several of these underline the need to improve the evidence base by conducting more research which uses longitudinal rather than cross sectional data (Benach et al., 2014; Frasquilho et al., 2016; Glonti et al., 2015). There is also a need for more research which examines risk and resilience factors at the individual level, as well as wider determinants affecting whole communities (Zivin et al., 2011). Research from an international literature review indicated relatively consistent evidence across Europe showing that suicides increased and mental health deteriorated during the 2008 recession (Parmar et al., 2016) - although not in countries with stronger social security systems (Copeland et al., 2015) - and research using data from the European Social Survey 2006-2014 showed that development of depressive feelings was worse among the precariously employed and economically inactive than for those with unlimited work contracts (Reibling et al., 2017). This is in keeping with a larger evidence base of the effects of previous recessions in the 1980s and 1990s. However, most previous studies of the effects of recessions on mental health have used data on either individuals or areas; and they often rely on repeated cross-sectional study designs. This paper contributes to this international literature by using longitudinal data on individuals and areas combined. We assess how geographically variable changes in labour market conditions in Scotland - during a period of recession - related to individual health outcomes, whilst also controlling for individual risk factors.

Our research also draws upon a review of existing research, relevant for Scotland, on the associations we can observe between mental health outcomes in the population and indicators of trends in local labour markets. The strongest evidence comes from longitudinal studies, which combine data on individuals and on the places where they are living over time, and which examine how changing attributes of individuals and of places may be variably associated with subsequent changes in health outcomes. This kind of work requires large, longitudinal samples from the general population, as examined here, with sufficient numbers in each of the local areas being compared to allow analysis of area, as well as individual variability. Many of the existing studies on recent trends in mental health in the UK (Astell-Burt and Feng, 2013; Barr et al., 2012, 2015; Brenner et al., 2014; Katikireddi et al., 2012; Laaksonen et al., 2009; Meltzer et al., 2010; Toffolutti and Suhrcke, 2014) rely on information on individuals' self-reports of health and service use, rather than on independent medical evidence about their use of health care for diagnosed conditions. Available evidence from England suggests that the proportion of people with mental illness who have received care has reduced since 2008 (Docherty and Thornicroft, 2015). Where information on NHS health care use has been examined (Barr et al., 2015) this has been for aggregated populations, rather than at individual level, making it impossible to assess whether associations with area conditions as well as personal attributes and behaviours are significant.

A few studies do focus on local or regional variability in the links between mental illness and economic conditions within the UK. Several of these were reviewed by the Faculty of Public Health (Faculty of Public Health, (undated)). Most relevant to the present research is work by Astell-Burt and Feng (Astell-Burt and Feng, 2013) who examined data for UK regions. The authors distinguished between Strathclyde region (including the city of Glasgow, Scotland's largest city) and the rest of Scotland for the period to 2010. They used data from the Quarterly Labour Force Survey (in which individuals are followed up for 5 quarterly survey rounds, but not over the longer term). Their study suggests that there were regional differences between Strathclyde and the rest of Scotland in the pattern of change in health during the recession and this underlines the need to make a more detailed analysis of local variation in Scotland to examine which parts of the country need to be given priority in consideration of public mental health and mental health care impacts of the recent economic down-turn. We have not identified research in Scotland, for longitudinal cohorts, which has examined whether individuals' mental health experience is associated with more local variability in local trends in employment. As noted above there is also a lack of studies from other countries using longitudinal approaches (Frasquilho et al., 2016). Our research uses information on employment trends at the scale of Local Authorities to examine the situation regarding the significance of trends in economic inequality for different parts of Scotland.

Reports on mental health care use for the population of Scotland have been produced by NHS Scotland and by Non-Governmental Organizations (eg, Mental Health Foundation, 2016). These suggest some upward trend in prescriptions for certain types of mental illness in the period since 2006 (McTaggart, personal communication, 2016) and comments on how prescription patterns vary according to socio-demographic factors like gender and age (Francis and McTaggart, 2015). It has also been reported (Schofield et al., 2016) that, compared with England and Wales, Scotland has shown a growing excess mortality due to self-harm, allowing for differences in deprivation, and Scottish policies have sought to protect mental health care provision against austerity cuts. It is recognized that more evidence is needed to quantify the nature of the relationship between employment during economic recession and health in the population. A recent policy statement by NHS Health Scotland (NHS Health Scotland, 2015; p6) has called for application of a 'public mental health approach, which ensures mental health is represented across all policy and works to address the social, environmental and individual determinants of mental health' and calls for an approach which is 'universal, yet calibrated to the level of disadvantage ... providing action proportionate to the level of need' in the population'. This report 
Conceptual Framework illustrating relationships being tested between KEY 'GROUPS' OF DETERMINANTS, CAPITALISED IN RED

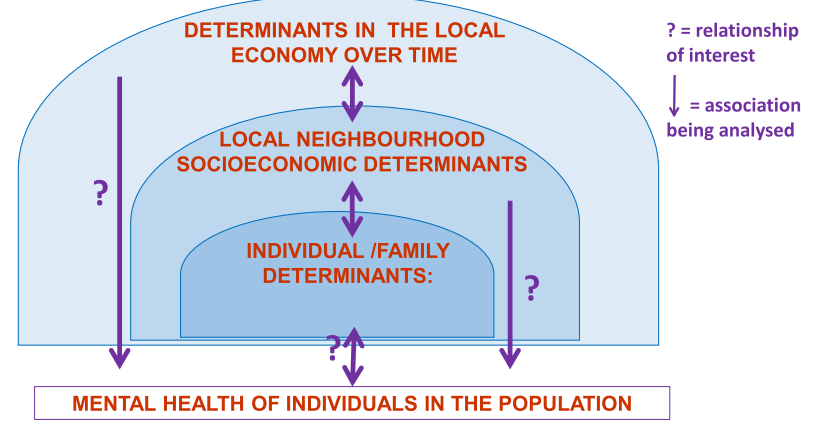

Fig. 1. Conceptual Framework illustrating relationships being tested between.

(NHS Health Scotland, 2015; p18) also recommended action to 'strengthen information systems, evidence and research', and greater 'exploration and use of national and local data' (NHS Health Scotland, 2015; p19). It has also been noted (ScotPHO, 2012) that there is a lack of time trend data showing how mental health has been changing over recent years, which is seen to be a gap in the evidence base to support the public mental health approach.

The conceptual model for this research is summarised diagrammatically in Fig. 1, which draws on the diagram summarising the wider determinants of health first promulgated by Dalghren and Whitehead (Dahlgren and Whitehead, 1991). Fig. 1 focusses on aspects of the wider determinants of health associated with work and employment, and reflects the idea that employment conditions in the wider regional economy will interact with both local socio-economic conditions in a person's neighbourhood, and with their individual risk factors for health (particularly sex, age, marital status and whether the person lives alone, their social position and personal employment status). The analysis described below assumes that each of these factors will also have some 'independent' relationship with individual health status, given that the person's health depends on the 'sum of their experiences' of individual risk factors, local neighbourhood processes and the changing conditions in their wider socio-economic environment. The question of particular interest here is whether change in the wider economy may directly influence individual psychological health, as well as possibly operating 'indirectly' on personal health (through effects on personal risk factors). It is hypothesised, for example (though we cannot test the detailed causal mechanisms here), that one's perception and experience of recession in the regional economy may generate psychological worry and stress that may directly impact on one's mental health. For example, research from a UK sample (Heyes et al., 2017) found that the negative wellbeing consequences of dissatisfaction with opportunities to make use of their abilities, and with working hours became more substantial between 2005 and 2012. This suggests that difficult labour market conditions can be damaging for mental health of workers still in employment, as well as those who become unemployed (Kivimäki et al., 2003; Bartley et al., 2011; Bambra, 2011). We explore this point further below in our analysis. If this is the case then (as discussed in the conclusion), policy for mental health care may need to consider wider determinants operating at the scale of regional labour markets, as well as more personal and "proximal' risk factors.

\section{Methodology}

Our methodology involved the use of information from three types of data, reflecting the key elements shown in Fig. 1. Firstly, we drew on Scottish Longitudinal Study (SLS) information from the census, on over 123,000 individual residents in Scotland, relating to their personal circumstances in 2011. Secondly, (using local census statistical output areas where the members of the SLS were living) we analysed data on neighbourhood socio-economic conditions prevailing in 2001, prior to the onset of the recession. Thirdly, we used information for the Local Authority areas where the SLS sample were living in 2011, categorizing trends in employment for the period 2006-2011. Below we explain how these three types of variables were generated for this analysis and the analytical method used.

\subsection{Data from the scottish longitudinal study on individual mental health and individual risk factors}

The SLS provides a valuable resource for work of this type, since it consists of a large $(5.3 \%)$ representative sample of the Scottish population drawn from population censuses and followed across time since 1991. For this research we have used SLS information for sample members who were included in the 2001 and 2011 censuses and were aged 16-59 years in 2001, since the vast majority of this age group would have been living in Scotland and of working age during the period of interest between 2007 and 2011. For this analysis we include data collected in the population censuses in 2001 and 2011 on: selfreported illness; various individual attributes (comprising demographic and socioeconomic 'risk factors' for long term illness).

Information on mental illness was collected in the 2011 population census in Scotland using the following question: 'Do you have any of the following conditions which have lasted, or are expected to last, at least 12 months?' - followed by a multiple choice question about long standing health problems the person might have experienced, with a list of options including: 'Mental Health Condition'. The measure of mental illness in this study therefore relates to perception of health at one time point, at the end of the period studied and is based on self-assessment. Some of those reporting a mental health condition may have been experiencing mental illness since before 2007. Figure A in Electronic Appendix A summarises the relationship between self-reporting of mental illness and of long term health conditions more generally. It shows that while there is some association between these two indicators they are distinct. This accords with results reported by Cohen et al. (1995).

Our analysis took into account information derived from the SLS on individual risk factors for mental health conditions that are widely reported in the literature, including the publications reviewed above, and in information published for Scotland on prescription of drugs commonly used to treat mental health conditions (Gronowski and McNicol, 2017). We included sex (in view of the greater prevalence of mental illness among women), and age in years. Other research on different types of long term illness may use a squared function of age to reflect increasing risk of many chronic conditions in older age groups. However this was not appropriate here since preliminary tests on the data analysed (not reported in detail here) showed that (as in other published studies on mental illness) risk of reporting a mental health condition increases from younger adulthood into middle age, before declining in older age. We also included information for 2011 on the person's individual and family circumstances which might vary over time. Data for 2011 were used in order to control for conditions which were prevalent in 2011 when selfreported mental health was recorded. These 'individual' variables included their marital status and whether they lived alone, because those who are not in marital relationships (especially among men) and those who live alone are at greater risk of mental illness. Individual socioeconomic status in 2011 was included since those in lower social status groups are more at risk of mental health conditions. Our social class measure is based on widely used classifications derived from type of occupation, ranging from Grade 1, Professional groups to Grade 5, Unskilled Manual workers (Individual income is not recorded in population censuses in the UK). We also included information on whether the person was recorded as unemployed and looking for work in 2011. This was used to assess whether the impact of being out of work at this stage of the economic recession would account for variation in mental health associated with labour market trends. 
3.2. Data on the local socio-economic conditions prevailing in the person's place of residence before the economic recession

The SLS records place of residence for the individuals in the study at each census. This meant that we were able to establish a 'baseline' indicator of the level of poverty in the person's neighbourhood in 2001, before the recession started to take effect. This is theoretically necessary in order to control for impacts of the local socio-economic conditions that the person would have been experiencing before the recession. The indicator used is the Carstairs Index of socio-economic deprivation, which has been recommended over other local socio-economic indicators for research on inequalities in health in Scotland (Fischbacher, undated). This comprises information on four proxy measures of deprivation: low occupational social class, lack of car ownership, overcrowding and male unemployment. We considered the potential to include data on trends in deprivation (Norman, 2015) for small localities (Scottish Output Areas) 2007-2011, similar to those relating to employment for Local Authorities, discussed below. However, Carstairs Deprivation indicators can only be generated for Output Area (OA) of residence in census years (2001 and 2011). At the time when the data were set up for this study, year on year indicators, taking into account residential mobility measured at this scale, and OA boundary changes, were not available for the period of interest, 2007-2011.

\subsection{Data on local authority labour market trends, linked to the SLS}

Scotland is divided administratively into 32 Local Authority areas for local government. These areas approximate quite closely to 'travel to work' areas in Scotland and in this study they are used as proxy definitions of labour market areas, for assessment of local variation in labour market trends. Local Authority areas are also of special interest as they are the units within which local health and social care planning is carried out. Data on employment rates in Local Authorities (NOMIS Official Labour Market Statistics, Office for National Statistics, at Durham University) were linked to the SLS members according to their place of residence in 2011. Temporal variation in area conditions may not follow 'linear' trends, so we used trajectory modelling analysis (Nagin and Odgers, 2010) to capture spatial variation in complex temporal trends. Using software designed to run as a Stata programme (Jones and Nagin, 2013), we classified the 32 local authorities in Scotland according to trends in employment rates 2007-2011. We found that employment trajectories in local authorities during the recent recession have varied across Scotland during the period and we identified four groups of local authorities showing different trajectories of change in employment rate, as shown in Fig. 2. In the analysis reported below, these four trajectory categories are used as indicators of the local economic impact of the recession that began to affect the UK and other countries globally since 2007 .

We report results of multilevel logistic regression on individual SLS members aged $16-59$ years in 2001 . The analysis was designed to assess the association between reporting of a mental health condition in 2011 (the dependent variable) and the type of employment trajectory in the person's local authority of residence, after controlling for the other individual/neighbourhood risk factors. The binary dependent variable for our analysis indicated: whether a mental illness was reported in 2011. To test the association between individually reported mental health conditions and area trends in employment, we conducted multi-level, multivariate logistic regression using the Stata 'meqrlogit' programme. The analysis also controls for the other variables summarised above (sex, age, marital status in 2011, whether the person lived alone in 2011, socio-economic position, whether unemployed in 2011, and decile categories of the Carstairs measure of deprivation for the area of residence in 2001). The levels of analysis included were the individual and the local authority in which they were living. For this analysis, the Carstairs indicator of deprivation in the person's immediate neighbourhood has been treated as an individual level indicator. In addition, we ran a sensitivity test for the impact of migration between local authorities, using a stratified analysis which includes only those living in the same Local Authority in 2001 and 2011. This does not control for all residential mobility, but it does suggest some confirmation that the relationships reported below were unlikely to have arisen from 'health selective' migration of individuals between local authorities. See Table A, Electronic Appendix A.

\section{Results}

\subsection{Distribution of the SLS members in areas with varying labour market trajectories}

We report results of analyses on over 120,000 individuals from the SLS aged between 16 and 59 years in 2001 for whom relevant data were available. Table 1 summarises the geographical distribution of 124,586 individuals who were recorded in the 2001 and 2011 census. Their area of residence in 2011 is classified according to the 4 'Groups' of local authorities identified in the trajectory modelling. The majority were living in area Groups 1 or 2, which include the more urbanised parts of Southern Scotland, while a smaller proportion were in Groups 3 and 4, mainly located in the highlands and islands to the north of the country (Fig. 2). The analyses reported below used Group 1 as the reference, including about $31 \%$ of the sample. This Group includes 9 local authorities, including the city of Glasgow and surrounding areas, and the graph in Fig. 2 shows that employment rates were relatively low and stable throughout the period studied. Glasgow is known to be a part of the country which, over a long period, has been shown to be relatively disadvantaged in terms of levels of deprivation and poor health, as compared with the rest of Scotland and the UK. About $51 \%$ of the sample were in areas in Group 2, which includes a diverse Group of 16 local authorities, including Edinburgh, another major urban centre in the country. As indicated in Fig. 2, this Group of areas had relatively high employment rates at the start of the period 2007-2011, but showed a significant decline and was beginning to approach the low levels seen in Glasgow by the end of the period. Those living in areas

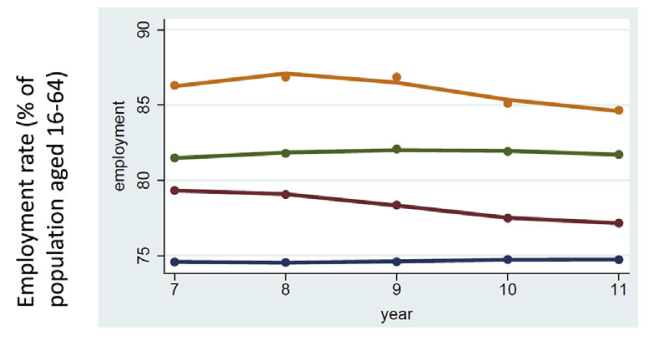

Legend:

1 = low employment throughout

(eg Glasgow) (9 LAs)

2 = falling employment

(eg Edinburgh) (16 Las)

$3=$ higher, levelling employment

(eg Aberdeen) (5 LAs)

$4=$ high, but declining employment

(Orkney, Shetland Islands) (2 LAs)

Years 2007-2011

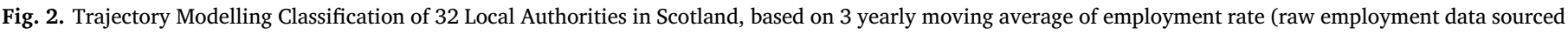
from NOMIS https://www.nomisweb.co.uk/)). 
Table 1

Trajectory group of residence in 2011 for SLS members aged 16-59 in 2001. Source: SLS

\begin{tabular}{crr}
\hline Employment Trajectory group of LA of residence in 2011 & Frequency & Percent \\
\hline 1 & 38,428 & 30.84 \\
2 & 63,808 & 51.22 \\
3 & 21,273 & 17.07 \\
4 & 1,077 & 0.86 \\
\hline Total & 124,586 & 100 \\
\hline
\end{tabular}

classed in Groups 3 and 4 respectively, make up approximately $17 \%$ and $1 \%$ of the sample. Group 3 includes mainly highland areas, including extensive rural areas as well as some urban locations such as the city of Aberdeen (where until quite recently the economy was boosted by the off-shore oil industry) with a relatively high level of employment throughout the period. The highest area employment rates were in the relatively remote, predominantly rural settings that make up Orkney and the Shetland Islands. Although the employment rate in these areas was beginning to fall over the period studied it remained relatively higher than in other parts of Scotland.

\subsection{Reported mental health in relation to changing labour market conditions and other risk factors}

Table 2 shows that $5.5 \%$ of the SLS members studied reported a mental health condition in 2011. This is a smaller proportion than we would expect to have experienced a mental health problem at some point during that year (for example, it is estimated that 1 in 3 people are affected by Mental Health problems each year (Scottish Government, undated) and $14 \%$ of those completing the Clinical Interview Schedule in the 2009 Scottish Health Survey were likely to have had a mental health problem in the previous few weeks (NHS Health Scotland, 2012). Our finding here may reflect the fact that the information on mental health is self-reported, rather than a clinical assessment, and was collected for each person at one time point only. Also, the census question was framed to refer to mental health problems expected to last at least a year.

The analysis reported in Table 3 is for 123,804 individuals aged 16-59 in 2001 for whom data were available on all the variables used in the analysis. The odds ratios and probability coefficients indicate significant associations of self-reported mental illness with the individual risk factors. This corresponds to findings published in the literature reviewed above. Women have a higher odds ratio of reporting a mental health condition than men. The relationship with age suggests that those in the oldest age groups have a lower risk than those who are younger (reflecting other research suggesting that the risk tends to peak around $40-50$ years and decline thereafter). The odds ratio of a mental health condition is significantly associated with social class, and risk is markedly higher for those in the most disadvantaged grades (4 and 5) compared with the most privileged class (grade 1). Compared with those who are married, people in other marital status categories (with the exception of widowhood) have a greater odds ratio of a mental health condition. Those living alone also have a significantly higher

\section{Table 2}

Whether a mental health condition was reported in 2011 for SLS members aged 16-59 in 2001.

Source: SLS

\begin{tabular}{crc}
\hline $\begin{array}{c}\text { Whether reported a mental health condition in the 2011 } \\
\text { census }\end{array}$ & Frequency & Percent \\
\hline $\begin{array}{c}\text { Does not report a mental health condition } \\
\text { Reports having a mental illness } \\
\text { Total }\end{array}$ & $\begin{array}{r}117,672 \\
6,885\end{array}$ & $\begin{array}{r}94.47 \\
5.53\end{array}$ \\
& 124,557 & 100 \\
\hline
\end{tabular}

risk. It is interesting to note that those who were unemployed in 2011 have a slightly lower odds ratio (after controlling for the other variables) but this is not a significant association. Compared with the least deprived areas, there is a significantly positive association of risk with increasing decile ranks of the Carstairs deprivation indicator in the place where the person lived in 2001. This shows that the analysis is at least partly controlling for area deprivation and unemployment experienced prior to the recent recession.

In terms of the main question addressed here, the result for the association with the employment trajectory of one's LA of residence is of particular interest. This shows that, compared with residents in LAs in Group 1, those in areas classed in Groups 3 and 4 have a significantly lower odds ratio of reporting a mental illness ( 0.83 and 0.56 respectively). Compared with Group 1, the odds ratio is slightly, but not significantly lower (0.92) for those in group 2 (where the employment rate started at a relatively high level, similar to Group 3, but trended downwards during the recession to approach the conditions in Group 1). The significant chibar indicator showed that there is significant variation at the level of the local authority of residence, which is not all accounted for by the predictor variables included in the analysis.

Table 4 reports results of a similar analysis carried out on a subsample of 121,335 people, excluding those who were unemployed and seeking work in 2011. This explores the idea that actually being unemployed is not the only factor that might generate stress for those in areas where employment rates are low or falling. The results for the association with LA employment trajectory are very similar to those in Table 3. This shows that the relationship with area employment trend holds significantly for those who were not unemployed in 2011.

Table A in an electronic appendix shows similar results for a similar model to that presented in Table 4, for a stratified group of the individuals analysed, who were recorded as living in the same local authority in 2001 and 2011. The results are consistent with those in Table 3 and Table 4.

\section{Discussion and conclusion}

Our findings are of relevance to the international research agendas reviewed above and particularly underline the need for a longitudinal perspective on the health impacts of recession, and the value of a perspective which is sensitive to variations in socio-economic determinants at various geographical scales. We comment below on possible interpretations of our findings regarding the impacts of recession on mental health, the policy significance of these results and on the scope for further analysis to address some of the limitations of the work to date.

This needs to be prefaced by a caveat regarding the limitations of this analysis. We have noted some limitations in the indicator of mental health condition used in this research. This may be an indicator of relatively severe mental illness which was having a significant impact on the person over a protracted period, although further research is needed to test this. It is also important for this study that the indicator has only been collected in one population census to date. It would be valuable to use the question in a subsequent census or large longitudinal population survey to assess whether it could be used to indicate change in mental health over time. Another limitation of the research is that we have not fully controlled for residential migration in this analysis, and this may have caused variation in experience of local conditions for individuals in this study. This is important since several studies, including some reviewed above, suggest that experience of local conditions over the lifecourse may have significance for health (Boyle et al., 2004; Curtis et al, 2003; Norman and Boyle, 2014). It is therefore feasible that over time individuals move between locations with distinct geographical contexts such as local levels of unemployment. We also note that if migration was selective (Norman et al., 2005) in relation to employment status, this might also have influenced the trends in employment rates that we used to classify local authorities. (However we do control 
Table 3

Results of Multilevel Logistic regression analysis of SLS members aged 16-59 in 2001. Dependent variable: Whether a Mental Health condition was reported in 2011. Source: SLS

\begin{tabular}{|c|c|c|c|c|c|c|c|}
\hline \multirow{2}{*}{$\begin{array}{l}\text { Predictor variables } \\
\text { sex (reference }=\text { male) }\end{array}$} & category & \multirow{2}{*}{$\begin{array}{l}\text { Odds Ratio } \\
1.280\end{array}$} & \multirow{2}{*}{$\begin{array}{l}\text { Std Error } \\
0.035\end{array}$} & \multirow{2}{*}{$\mathrm{Z}$} & \multirow{2}{*}{$\begin{array}{l}\mathrm{P}>|\mathrm{z}| \\
0.000\end{array}$} & \multicolumn{2}{|c|}{$95 \%$ confidence interval } \\
\hline & female & & & & & 1.214 & 1.349 \\
\hline age recorded in 2001 & age in years & 0.992 & 0.001 & -6.56 & 0.000 & 0.989 & 0.994 \\
\hline \multirow[t]{4}{*}{ social grade $2011($ reference $=1)$} & 2 & 1.493 & 0.074 & 8.14 & 0.000 & 1.356 & 1.644 \\
\hline & 3 & 1.431 & 0.075 & 6.84 & 0.000 & 1.291 & 1.586 \\
\hline & 4 & 2.378 & 0.119 & 17.33 & 0.000 & 2.156 & 2.623 \\
\hline & 5 & 5.880 & 0.355 & 29.31 & 0.000 & 5.223 & 6.619 \\
\hline employment status 2011 (ref = not unemployed) & unemployed & 0.895 & 0.052 & -1.89 & 0.059 & 0.798 & 1.004 \\
\hline \multirow[t]{4}{*}{ marital status 2011 reference $=$ married } & single & 1.649 & 0.064 & 12.87 & 0.000 & 1.528 & 1.779 \\
\hline & separated & 2.117 & 0.116 & 13.65 & 0.000 & 1.901 & 2.357 \\
\hline & divorced & 1.893 & 0.081 & 14.86 & 0.000 & 1.740 & 2.059 \\
\hline & widowed & 0.917 & 0.070 & -1.14 & 0.254 & 0.790 & 1.064 \\
\hline \multirow{10}{*}{$\begin{array}{l}\text { Whether lived alone } 2011 \text { (ref = lives with other(s) } \\
\text { carstairs deprivation indicator LSOA (deciles) } \\
\text { (reference }=1 \text {; least deprived) }\end{array}$} & lives alone & 1.968 & 0.067 & 19.90 & 0.000 & 1.841 & 2.104 \\
\hline & 2 & 1.346 & 0.102 & 3.94 & 0.000 & 1.161 & 1.561 \\
\hline & 3 & 1.353 & 0.102 & 4.00 & 0.000 & 1.167 & 1.569 \\
\hline & 4 & 1.502 & 0.112 & 5.47 & 0.000 & 1.298 & 1.737 \\
\hline & 5 & 1.591 & 0.117 & 6.30 & 0.000 & 1.377 & 1.839 \\
\hline & 6 & 1.778 & 0.129 & 7.94 & 0.000 & 1.542 & 2.049 \\
\hline & 7 & 2.013 & 0.143 & 9.82 & 0.000 & 1.750 & 2.314 \\
\hline & 8 & 1.983 & 0.141 & 9.64 & 0.000 & 1.725 & 2.279 \\
\hline & 9 & 2.354 & 0.165 & 12.22 & 0.000 & 2.052 & 2.701 \\
\hline & Most Deprived 10 & 2.663 & 0.187 & 13.93 & 0.000 & 2.320 & 3.056 \\
\hline \multirow[t]{3}{*}{ LA employment trajectory group $($ reference $=1$ ) } & 2 & 0.922 & 0.049 & -1.54 & 0.124 & 0.832 & 1.022 \\
\hline & 3 & 0.833 & 0.059 & -2.59 & 0.010 & 0.726 & 0.957 \\
\hline & 4 & 0.555 & 0.112 & -2.92 & 0.003 & 0.374 & 0.824 \\
\hline constant & & 0.015 & 0.001 & -43.75 & 0.000 & 0.013 & 0.018 \\
\hline Random-effects & Est & & Std. Error & & & $\%$ confid & \\
\hline ctydis: Identity & 0.009 & & 0.004 & & 0.004 & & 0.021 \\
\hline
\end{tabular}

LR test vs. logistic regression: chibar2 $(01)=22.12$ Prob $\geq$ chibar $2=0.0000$.

Notes on specification of regression model:

Mixed-effects logistic regression.

Number of observations $=123804$

Group variable: Local Authority.

Number of groups $=32$.

Observations per group: minimum $=497$ average $=3868.9$ maximum $=11683$.

Integration points $=7$ Wald chi2(16) $=4552.95$.

Log likelihood $=-23577.93$ Prob $>$ chi2 $=0.0000$.

for local neighbourhood risk factors pertaining to 2001, which might have affected individual mental health prior to the recession period of interest in this study, and we report in Appendix Table A a simple sensitivity test for possible effect of residential migration on the results, in light of which our findings do not change.)

We would also emphasise that the outcome of the trajectory modelling procedure, that generated the classification of area employment trends used here, depends on the ways that the modelling is specified, so that alternative definitions of employment trend could be considered. Other aspects of Local Authority geography (for example rurality) may also show an association with the employment trend classification, so that it is possible that employment rate in itself is not the underlying causal variable accounting for the associations shown here.

We also considered the potential to include data on trends in deprivation for OAs 2007-2011, eg: as applied for English LSOAs (Norman and Riva, 2012; Norman, 2015), similar to those relating to employment for Local Authorities, discussed below. However, Carstairs Deprivation indicators are available only for 2001 and 2011 (and for earlier decennial census years). Year on year indicators were not available for this project for the whole period 2001-2011. SLS data on OA of residence in 2001 and 2011 available for this study did not allow us to fully control for change in OA boundaries over time.

Bearing in mind these limitations, our findings seem to lend support to the idea that the trend in employment over time (as an aspect of the life course of a place) has significance for mental health. This association is independent of the individual's personal employed or unemployed status (and in fact our analysis suggests that, controlling for other factors, being unemployed was not associated with greater risk of a mental health condition). The results seem consistent with the idea put forward by authors reviewed above that stress and anxiety for those in work (which may be exacerbated due to labour market conditions during a recession) may be at least as important for mental health as the experience of being unemployed. Also, people who are not unemployed themselves, but are living in households where another household member becomes unemployed may be impacted indirectly by reductions in employment levels. It is interesting to note that the risk of a mental health condition was lower for people living in the two groups of areas that maintained relatively high and steady levels of employment. In contrast, those in areas where employment trend is classed in Group 2 (most clearly characterised by worsening labour market conditions) did not have significantly different risks of mental ill-health than those in Group 1 where employment rates were persistently low throughout the period.

A large literature has drawn attention to the relatively disadvantaged health status of the population in areas such as Glasgow, in Group 1 (Norman et al., 2011)). This emphasis on the 'Glasgow effect' has recently begun to be criticised, however, as an over-simplification of the pattern of health inequality in Scotland. Our results may also suggest that commentaries focussing strongly on the idea of the 'Glasgow effect' may not fully describe the pattern of mental health inequality in Scotland. Here we see that mental health of those in the group of areas including Glasgow and nearby areas was not 
Table 4

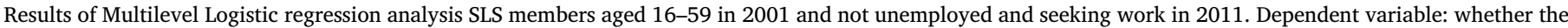
person reported a mental health condition in 2011.

Source: SLS

\begin{tabular}{|c|c|c|c|c|c|c|c|}
\hline Predictor variables & category & Odds Ratio & Std Error & $\mathrm{z}$ & $P>|z|$ & $95 \%$ inter & confidence val \\
\hline Sex $($ reference $=$ male $)$ & female & 1.266 & 0.035 & 8.56 & 0.000 & 1.199 & 1.336 \\
\hline age recorded in 2001 & age in years & 0.992 & 0.001 & -6.47 & 0.000 & 0.989 & 0.994 \\
\hline social grade $2011($ reference $=1)$ & 2 & 1.486 & 0.074 & 7.95 & 0.000 & 1.348 & 1.638 \\
\hline & 3 & 1.423 & 0.075 & 6.65 & 0.000 & 1.283 & 1.579 \\
\hline & 4 & 2.411 & 0.122 & 17.40 & 0.000 & 2.184 & 2.663 \\
\hline & 5 & 6.462 & 0.399 & 30.23 & 0.000 & 5.726 & 7.293 \\
\hline marital status 2011 reference $=$ married & single & 1.637 & 0.065 & 12.51 & 0.000 & 1.515 & 1.769 \\
\hline & separated & 2.104 & 0.118 & 13.22 & 0.000 & 1.884 & 2.349 \\
\hline & divorced & 1.894 & 0.083 & 14.62 & 0.000 & 1.738 & 2.063 \\
\hline & widowed & 0.894 & 0.068 & -1.48 & 0.138 & 0.771 & 1.037 \\
\hline Whether lived alone 2011 (ref = lives with other(s) & lives alone & 1.967 & 0.069 & 19.30 & 0.000 & 1.836 & 2.107 \\
\hline carstairs deprivation indicator LSOA (deciles) & 2 & 1.347 & 0.103 & 3.91 & 0.000 & 1.160 & 1.564 \\
\hline (reference $=1 ;$ least deprived) & 3 & 1.360 & 0.104 & 4.02 & 0.000 & 1.171 & 1.580 \\
\hline & 4 & 1.511 & 0.114 & 5.48 & 0.000 & 1.304 & 1.751 \\
\hline & 5 & 1.585 & 0.118 & 6.16 & 0.000 & 1.369 & 1.835 \\
\hline & 6 & 1.787 & 0.131 & 7.90 & 0.000 & 1.547 & 2.064 \\
\hline & 7 & 2.004 & 0.145 & 9.62 & 0.000 & 1.739 & 2.309 \\
\hline & 8 & 1.972 & 0.142 & 9.42 & 0.000 & 1.712 & 2.271 \\
\hline & 9 & 2.350 & 0.167 & 12.00 & 0.000 & 2.044 & 2.702 \\
\hline & Most Deprived 10 & 2.731 & 0.195 & 14.07 & 0.000 & 2.374 & 3.141 \\
\hline LA employment trajectory group (reference $=1$ ) & 2 & 0.917 & 0.048 & -1.63 & 0.102 & 0.827 & 1.017 \\
\hline & 3 & 0.827 & 0.058 & -2.70 & 0.007 & 0.720 & 0.949 \\
\hline & 4 & 0.564 & 0.113 & -2.85 & 0.004 & 0.380 & 0.836 \\
\hline constant & & 0.015 & 0.001 & -43.55 & 0.000 & 0.013 & 0.018 \\
\hline Random-effects & & Est & \multicolumn{2}{|c|}{ Std. Error } & \multicolumn{2}{|c|}{$95 \%$ Inter } & Conf. val \\
\hline ctydis: Identity & & 0.009 & \multicolumn{2}{|c|}{0.004} & \multicolumn{2}{|c|}{0.004} & 0.022 \\
\hline
\end{tabular}

LR test vs. logistic regression: chibar2(01) $=16.96$ Prob $\leq$ chibar $2=0.0000$.

Notes on specification of regression model:

Mixed-effects logistic regression Number of obs $=121335$.

Group variable: ctydis (Local Authority) Number of groups $=32$.

Obs per group: $\min =493$; Obs per group: $\min =493$ avg $=3791.7 \max =11271$.

Integration points $=7$.

Wald chi2(15) $=4537.91$.

Log likelihood $=-22707.166$.

Prob $>$ chi $2=0.0000$.

significantly worse than in other areas, classed in Group 2. In contrast, our findings tend to draw attention more strongly towards a possible, beneficial 'highlands and islands effect', relating to conditions associated with comparatively good mental health. We suggest that more research needs to be carried out on what may make mental health in these northerly parts of Scotland more resilient to potential economic threats during the recent recession. This question is the focus of further research which we are undertaking at present.

We are also extending this analysis by linking the SLS participants data to prescriptions provided by the National Health Service for mental disorders, in order to capture information on medical treatment of mental health conditions over time. This will help to address some of the limitations associated with the self-reported mental health indicator used in this study.

In terms of policy significance, therefore, we conclude that our research underlines that public health policy to address the potential impacts of deprivation and economic downturn in Scotland should include consideration of what may be sub-regional variability and perhaps rather different processes determining mental health in different parts of the country. Future research should also explore the role of austerity policies and their uneven socio-spatial impacts on both employment (e.g. due to public service workforce cuts) and mental health (e.g. via reductions in welfare benefits). Our findings also contribute to theoretical and empirical agendas in health geography by demonstrating the importance of research that takes a longitudinal perspective and focusses on changing conditions in places as well as in individual circumstances of people.

\section{Acknowledgements}

The help provided by staff of the Longitudinal Studies Centre Scotland is acknowledged. The LSCS is supported by the ESRC/JISC, the Scottish Funding Council, the Scientists Office and the Scottish Government.

The authors alone are responsible for the interpretation of the data. Census output is Crown copyright and is reproduced with the permission of the Controller of HMSO and the Queen's Printer for Scotland.

We also acknowledge help and advice from colleagues at:

the Centre for Research on Environment, Society and Health, University of Edinburgh;

the Administrative Data Research Centre, University of Edinburgh; NOMIS (Official Labour Market Statistics), Office for National Statistics at Durham University;

NHS Scotland.

This research is supported by the Economic and Social Research Council, UK, grant award ES/P008585/1.

We are grateful to Dr Mylene Riva, University of McGill, Quebec, Canada, for helpful advice regarding our methodology. The authors also thank the anonymous peer reviewers for their helpful reccommendations.

\section{Appendix A. Supplementary data}

Supplementary data related to this article can be found at https:// doi.org/10.1016/j.socscimed.2018.08.003. 


\section{References}

Astell-Burt, T., Feng, X., 2013. Health and the 2008 economic recession: evidence from the United Kingdom. PLoS One 8.

Bailey, A.J., 2009. Population geography: lifecourse matters. Prog. Hum. Geogr. 33 (3), 407-418.

Bambra, C., 2011. Work, Worklessness and the Political Economy of Health. Oxford University Press, Oxford.

Bambra, C., 2016. Health Divides: Where You Live Can Kill You. Policy Press, Bristol.

Barr, B., Taylor-Robinson, D., Scott-Samuel, A., McKee, M., Stuckler, D., 2012. Suicides associated with the 2008-10 economic recession in England: time trend analysis. Br. Med. J. 345.

Barr, B., Kinderman, P., Whitehead, M., 2015. Trends in mental health inequalities in England during a period of recession, austerity and welfare reform 2004 to 2013 . Soc. Sci. Med. 147, 324-331.

Bartley, M., Ferrie, J., Montgomery, S.M., 2011. Health and labour market disadvantage: unemployment, non-employment, and job insecurity. In: In: Marmot, M., Wilkinson, R.G. (Eds.), Social Determinants of Health, vol. 2006. Oxford University Press, Oxford, pp. 78-96.

Benach, J., Vives, A., Amable, M., Vanroelen, C., Tarafa, G., Muntaner, C., 2014. Precarious employment: understanding an emerging social determinant of health. In: In: Fielding, J.E. (Ed.), Annual Review of Public Health, vol. 35. pp. 229-253.

Boyle, P., Norman, P., Rees, P., 2004. Changing places. Do changes in the relative deprivation of areas influence limiting long-term illness and mortality among non-migrant people living in non-deprived households? Soc. Sci. Med. 58, 2459-2471.

Brenner, M.H., Andreeva, E., Theorell, T., Goldberg, M., Westerlund, H., Leineweber, C., et al., 2014. Organizational downsizing and depressive symptoms in the european recession: the experience of workers in France, Hungary, Sweden and the United Kingdom. PLoS One 9.

Cherrie, M., Shortt, N., Mitchell, R., Taylor, A., Redmong, P., Ward-Thompson, C., Starr, J., Deary, J., Pearce, J., 2018. Green space and cognitive ageing: a retrospective life course analysis in the Lothian Birth Cohort, 1936. Soc. Sci. Med. 196, 56-65. https:// doi.org/10.1016/j.socscimed.2017.10.038.

Cohen, G., Forbes, J., Garraway, M., 1995. Interpreting self-reported limiting long-term illness. Br. Med. J. 311, 722-724.

Colombo, E., Rotondi, V., Stanca, L., 2018. Macroeconomic conditions and health: inspecting the transmission mechanism. Econ. Hum. Biol. 28, 29-37.

Copeland, A., Bambra, C., Nylen, L., Kasim, A.S., Riva, M., Curtis, S., Burstrom, B., 2015. All in it together? The effects of recession on population health and health inequalities in England and Sweden, 1991 to 2010. Int. J. Health Serv. 45 (45), 3-24.

Cummins, S., Curtis, S., Diez-Roux, A.V., Macintyre, S., 2007. Understanding and representing 'place' in health research: relational approaches. Soc. Sci. Med. 66, 1825-1838.

Curtis, S., Riva, M., 2010. Progress Report : Health Geographies I : complexity theory and human health. Prog. Hum. Geogr. 34, 215-223.

Curtis, S., Southall, H., Congdon, P., Dodgeon, B., 2003. Area effects on health variation over the life-course: analysis of the Longitudinal Study sample in England using new data on area of residence in childhood. Soc. Sci. Med. 58, 57-74.

Dahlgren, G., Whitehead, M., 1991. Policies and Strategies to Promote Social Equity in Health. Institute for Futures Studies, Stockholm, Sweden.

Diez-Roux, A., Mair, C., 2010. Neighborhoods and health. Ann. N. Y. Acad. Sci. 1186 (1), 125-145.

Docherty, M., Thornicroft, G., 2015. Specialist mental health services in England in 2014: overview of funding, access and levels of care. Int. J. Ment. Health Syst. 9.

Faculty of Public Health (undated). The impact of the UK recession and welfare reform on mental health http://www.fph.org.uk/the impact of the uk recession and welfare reform_on_mental_health.

Ferrarini, T., Nelson, K., Sjoberg, O., 2014. Unemployment insurance and deteriorating self-rated health in 23 European countries. J. Epidemiol. Community 68, 657-662.

Fischbacher, C. (undated). Identifying "deprived Individuals": Are There Better Alternatives to the Scottish Index of Multiple Deprivation (SIMD) for Socioeconomic Targeting in Individually Based Programmes Addressing Health Inequalities in Scotland? . (Edinburgh)

Francis, J., McTaggart, S., 2015. The Influence of Deprivation, Gender and Age on the Use of Mental Health Medications Public Health and Intelligence. National Health Scotland (Poster).

Frasquilho, D., Matos, M.G., Salonna, F., Guerreiro, D., Storti, C.C., Gaspar, T., et al., 2016. Mental health outcomes in times of economic recession: a systematic literature review. BMC Publ. Health 16 (1), 115.

Gatrell, A.C., 2011. Mobilities and Health. Ashgate, Surrey, UK.

Glonti, K., Gordeev, V.S., Goryakin, Y., Reeves, A., Stuckler, D., McKee, M., et al., 2015. A systematic review on health resilience to economic crises. PLoS One 10.

Gronowski, K., McNicol, M., 2017. Gronowski and Williams NHS Scotland Medicines Used in Mental Health 2005/6- 2015/(October 2017 Report). NHS Health Scotland Information Services Division, Edinburgh, Scotland.

Heyes, J., Tomlinson, M., Whitworth, A., 2017. Underemployment and well-being in the UK before and after the great recession. Work. Employ. Soc. 31, 71-89.

Jones, B., Nagin, D.S., 2013. A notes on a Stata plug-in for estimating group-based trajectory models. Socio. Meth. Res. 42, 608-613.

Katikireddi, S.V., Niedzwiedz, C.L., Popham, F., 2012. Trends in population mental health before and after the 2008 recession: a repeat cross-sectional analysis of the 19912010 Health Surveys of England. Bmj Open 2.

Kivimäki, M., Vahtera, J., Virtanen, M., Elovainio, M., Pentti, J., Ferrie, J.E., 2003 Temporary employment and risk of overall and cause-specific mortality. Am. J. Epidemiol. 158, 663-668.
Kwan, M.P., 2004. GIS methods in time-geographic research: geo-computation and geovisulatisation of human activity patterns. Geogr. Ann. 86 (4), 267-280.

Laaksonen, E., Martikainen, P., Lallukka, T., Lahelma, E., Ferrie, J., Rahkonen, O., et al., 2009. Economic difficulties and common mental disorders among Finnish and British white-collar employees: the contribution of social and behavioural factors. J. Epidemiol. Community 63, 439-446.

Learmonth, A., Curtis, S., 2013. Place shaping to create health and wellbeing using Health Impact Assessment: health geography applied to develop evidence-based practice. Health Place 24, 20-22.

Lekkas, P., Paquet, C., Howard, N.J., Daniel, M., 2017. Illuminating the lifecourse of place in the longitudinal study of neighbourhoods and health. Soc. Sci. Med. 177, 239-247.

Macintyre, S., Ellaway, A., Cummins, S., 2002. Place effects on health: how can we conceptualise, operationalise and measure them? Soc. Sci. Med. 55 (1), 125-139.

Matthews, S.A., 2017. Uncertain geographic context problem. In: Douglas, R., Castree, N., Goodchild, M.M., Kobayashi, A., Weidong Liu, W., Marston, R.A. (Eds.), The International Encyclopedia of Geography. Wiley-Blackwell, Oxford.

Meltzer, H., Bebbington, P., Brugha, T., Jenkins, R., McManus, S., Stansfeld, S., 2010. Job insecurity, socio-economic circumstances and depression. Psychol. Med. 40, 1401-1407.

Mental Health Foundation, 2016. Voices of Experience,Scottish Government. Mental Health Foundation, Scotland A review of mental health serivces in Scotland: Perspectives an dExperiences of Service Users, Carers and Professionals. https:// www.mentalhealth.org.uk/publications/review-mental-health-services-scotland.

Murray, E.T., Ben-Shlomo, Y., Tilling, K., Southall, H., Aucott, P., Kuh, D., Hardy, R., 2013. Area deprivation across the life course and physical capability in midlife: findings from the 1946 British birth cohort. Am. J. Epidemiol. 178 (3), 441-450.

Nagin, D.S., Odgers, C.L., 2010. Group-based trajectory modeling in clinical research. Annu. Rev. Clin. Psychol. 6, 109-138.

NHS Health Scotland, 2012. Scotland's Mental Health: Adults 2012. NHS Health Scotland, Edinburgh. file:///C:/Users/Geography/Documents/Research\%202015-16/SLS \%20analysis/scotpho121019_mhadults2012_fullreport.pdf.

NHS Health Scotland, 2015. Good Mental Health for All. Scotland: NHS Scotland. NHS Health Scotland, Edinburgh. http://www.healthscotland.com/documents/25928. aspx.

NHS Scotland, 2018. The Place Standard Tool, Edinburgh \& Glasgow. NHS Health Scotland, Scotland. http://www.healthscotland.scot/tools-and-resources/the-placestandard-tool.

Norman, P., 2015. The Changing Geography of Deprivation in Britain: Exploiting Small Area Census Data 1971 to 2011. University of Leeds, Leeds. http://leeds.gisruk.org/ abstracts/GISRUK2015_submission_21.pdf.

Norman, P., Boyle, P., 2014. Are health inequalities between differently deprived areas evident at different ages? A longitudinal study of census records in England and Wales, 1991-2001. Health Place 26, 88-93.

Norman, P., Riva, M., 2012. Population health across space and time: the geographical harmonisation of the Office for national Statistics longitudinal study for England and Wales. Popul. Space Place 18, 483-502.

Norman, P., Boyle, P., Rees, P., 2005. Selective migration, health and deprivation: a longitudinal analysis. Soc. Sci. Med. 60, 2755-2771.

Norman, P., Boyle, P., Exeter, D., Feng, Z.Q., Popham, F., 2011. Rising premature mortality in the UK's persistently deprived areas: only a Scottish phenomenon? Soc. Sci Med. 73, 1575-1584.

Parmar, D., Stavropoulou, C., Ioannidis, J.P.A., 2016. Health outcomes during the 2008 financial crisis in Europe: systematic literature review. BMJ Br. Med. J. (Clin. Res. Ed.) 354 .

Paul, K.I., Moser, K., 2009. Unemployment impairs mental health: meta-analyses. J. Vocat. Behav. 74, 264-282 2009.

Pearce, J., 2018. Complexity and uncertainty in geography of health research: in corporating life-course perspectives. Ann. Assoc. Am. Geogr. https://doi.org/10. 1080/24694452.2017.1416280.

Pearce, J., Cherrie, M., Shortt, N., Deary, I., Ward-Thompson, C., 2018. Life course of place: a longitudinal study of mental health and place. Trans. Inst. Br. Geogr. https:// doi.org/10.1111/tran.12246. (in press).

Popham, F., Gray, L., Bambra, C., 2012. Employment status changes and the prevalence of self-rated health: findings from UK individual level repeated cross-sectional data from 1978 to 2004. BMJ Open 2, e001342. https://doi.org/10.1136/bmjopen-2012001342.

Reeves, A., McKee, M., Gunnell, D., Chang, S.-S., Basu, S., Barr, B., et al., 2015. Economic shocks, resilience, and male suicides in the Great Recession: cross-national analysis of 20 EU countries. Eur. J. Publ. Health 25, 404-409.

Reibling, N., Beckfield, J., Huijts, T., Schmidt-Catran, A., Thomson, K.H., Wendt, C. 2017. Depressed during the depression: has the economic crisis affected mental health inequalities in Europe? Findings from the European Social Survey (2014) special module on the determinants of health. Eur. J. Publ. Health 27, 47-54.

Riva, M., Bambra, C., Curtis, S.E., Gauvin, L., 2011. Collective resources or local social inequalities? A large scale examination of the protective role of employment on mental health in rural areas in England. Eur. J. Publ. Health 21, 197-203.

Schofield, L., Walsh, D., Munoz-Arroyo, R., McCartney, G., Buchanan, D., Lawder, R., et al., 2016. Dying younger in Scotland: trends in mortality and deprivation relative to England and Wales 1981 -2011. Health Place 40, 106-115.

ScotPHO, 2012. Scotland's Mental Health: Adults 2012. Public Health Information for Scotland, Edinburgh Scotland, ScotPHO.

Scottish Government (undated). Mental Health in Scotland. Edinburgh, UK: Mental Health Unit, Scottish Government. Edinburgh, UK. http://www.gov.scot/Topics/ Health/Services/Mental-Health.

Smith, S., Easterlow, D., 2005. The strange geography of health inequalities. Trans. Inst. Br. Geogr 30 (2), 173-190. 
Tefft, N., 2011. Insights on unemployment, unemployment insurance, and mental health. J. Health Econ. 30, 258-264.

Toffolutti, V., Suhrcke, M., 2014. Assessing the short term health impact of the Great Recession in the European Union: a cross-country panel analysis. Prev. Med. 64, 54-62.

Uutela, A., 2010. Economic crisis and mental health. Curr. Opin. Psychiatr. 23, 127-130. Van der Wel, K., Saltkjel, T., Chen, W.-H., Dahl, E., Halvorsen, K., 2018. European health inequality through the 'Great Recession': social policy matters. Sociology of Heath \& Illness XX, p1-10.

WHO, 2008. Closing the Gap in a Generation; Health Equity through Action on the Social Determinants of Health. World Health Organization, Geneva.

Zivin, K., Paczkowski, M., Galea, S., 2011. Economic downturns and population mental health: research findings, gaps, challenges and priorities. Psychol. Med. 41, $1343-1348$. 